\title{
Abstinência dos rituais fúnebres e seus impactos
}

\author{
Abstinence from funeral rituals and their impacts
}

\author{
Priscila Caroline Cordeiro Mendes ${ }^{\circ}$
}

Faculdade Única, Ipatinga, Minas Gerais, Brasil. Autor para correspondência. E-mail: cila_carol@hotmail.com

\begin{abstract}
Resumo: Introdução: O morrer faz parte da sociedade desde os primórdios e os rituais acompanham esse momento. A morte tem seu significado em cada cultura, contudo, no decorrer dos últimos anos, a pandemia tem ocupado um lugar social significativo, ao pensar que o mundo vive um luto coletivo. Diante da problemática, observa-se que a pandemia, além de causar impactos físicos e mudanças abruptas, altera também os rituais fúnebres. Com isso em vista, surge o questionamento acerca da saúde mental dos enlutados diante da privação da despedida como sempre ocorrera. Além das mortes em massa, a abstinência do adeus ritualizado e acompanhado é uma questão a analisar. Revisão: Trata-se de uma revisão bibliográfica na qual foi realizada uma pesquisa em livros e artigos indexados em plataformas digitais. Discussão: A morte é universalmente conhecida do mesmo modo que sua natureza é completamente intocável. A depender de qual cultura o homem esteja inserido, pensar e falar sobre a morte pode gerar um caos aos que estão próximo. Contudo, além de ser um assunto antigo, é totalmente inevitável e de suma importância para a vida. Afinal, entende-se muito sobre a vida observando como aquela cultura encara a morte. Considerações finais: A abstinência dos rituais fúnebres desorganiza o processo de luto, podendo desenvolver no enlutado um luto complicado, tornando-se relevante pensar em novas maneiras de ritualizar a perda durante o cenário pandêmico.
\end{abstract}

Palavras-chave: morte, luto, rituais, impactos na saúde mental.

\begin{abstract}
Introduction: Dying has been part of the society since the origin and the rituals have accompanied this moment. The death has its meaning in every culture, however, along these last years, the pandemic has occupied a meaningful social place, at the thought that the world lives a collective mourning. Facing the problematics, it is observed that pandemic, besides causing physical impacts and abrupt changes, it also alters the funeral rituals. With that in mind, it occurs the question about the mental health of the bereaved in front of farewell privation like has always occurred. Besides the mass deaths, the abstinence from ritualized and accompanied goodbye is a question to be analyzed. Review: It is about a bibliographic review in which has been realized a research in books and indexed articles in digital platforms. Discussion: The death is universally known at the same way its nature is completely untouchable. Depending on in what culture the man is inserted, thinking and talking about death can generate chaos to those are close to. However, besides being an old subject, it's totally unavoidable and of utmost importance for life. After all, it is understood a lot about the life observing how that culture faces death. Final considerations: The abstinence from funeral rituals disorganizes the process of mourning, and may develop in the bereaved a complicated bereavement, becoming relevant to think in other ways to ritualize the loss during pandemic scenario.
\end{abstract}

Keywords: death, mourning, rituals, impacts on mental health.

\section{Introdução}

O artigo nasce de uma inquietação despertada no atual cenário mundial em que a COVID-19 impõe ao individuo. Dentre as tantas limitações, medo e angustia vivenciadas nesse período, a ausência e/ou restrições que modificam os rituais fúnebres aprendidos e vividos de geração em geração tem sido uma das questões também a serem enfrentadas neste tempo atípico.

A pandemia está para além de uma crise epidemiológica somente, ela é caracterizada também por uma crise psicológica (Associação Americana de Psicologia, 2020 apud Giamattey, 2020). As máscaras, o isolamento, as mudanças, perdas e tantas incertezas, geram nas pessoas a um colapso muito além de questões físicas. A pandemia é uma ameaça, até mesmo para os rituais e cerimonias vividas e ensinadas desde os primórdios das civilizações.

Leakey, 1997 apud Souza e Souza, 2019, aponta que "desde a Pré-História, a emergência da consciência coincidiu com a emergência de uma preocupação com relação a finitude, através do cuidado ritualizado para 
com entes queridos mortos. " A finitude é uma questão complexa que o ser humano experiência no percurso. Logo, os rituais vêm realizando o papel organizador, auxiliando na maturação psicológica do novo ciclo imposto pela finitude.

São elementos tradicionais, passados de família para família e assim a sociedade foi se construindo. Vai além do palpável e visível, pensar sobre os rituais de despedida é trazer a importância deles para a elaboração de uma perda que fará parte daqueles que ainda estão em vida. Contudo, a conjuntura atual não permite a realização de despedidas como foram ensinadas e vivenciadas, hoje, a ausência desses e a modificação brusca tem algum impacto na psique dos que ficam?

A importância de buscar compreender os rituais de despedida e sua ação no homem implica em assimilar sua função e efeitos na saúde metal diante da finitude e perda. Ao mesmo tempo, corrobora com as reflexões a respeito de um futuro não muito distante, podendo até mesmo dizer, de uma atualidade em que profissionais da saúde mental já lidam em seus locais de atuação.

\section{Revisão e discussão}

Para a discussão, é utilizado o método de revisão de literatura, empregando os descritores morte, luto, rituais, simbolismo na psicologia. Buscando artigos indexados em plataformas digitais e também em livros. Baseando simbólico na abordagem psicanalista, referenciada pelo teórico Jung. Também, relatos de experiências vivenciadas em um Hospital de Campanha COVID-19, para fomentar a discussão e reflexão.

\section{Morte, Morrer, Finitude, Rito, Rituais e Luto}

"Dar-se conta da nossa finitude, da inevitabilidade da morte e do não ser é como encarar o sol: não conseguimos olhar de frente por muito tempo, simplesmente vivemos sem pensar que vamos morrer" (Maldonado apud Soares \& Mautoni, 2013).

Mesmo sendo a única certeza da vida, a morte é intangível ao ser humano. Ela é extremamente forte como o sol, sabe-se e sente-se o sol, até por um momento o homem busca encará-lo de frente, porém sua luz é tão irradiante que não o permite. Assim é a morte, sua existência é universalmente conhecida do mesmo modo que sua natureza é completamente intocável. Ninguém sabe ao certo sobre a morte, pois, quem já a vivenciou, não voltou para contar. A morte é, de fato, singular.

A morte se trata de um assunto intrigante, porém não é novo; alguns autores deixaram suas considerações a respeito, dentre elas: ela é reconhecida como natural, universal e inevitável, contudo, é impossível o homem encarar de frente a sua própria morte (Costa, 1999 apud Hohendorff \& Melo, 2009), com isso, a sociedade tende a esquivar-se do assunto em pauta (Kübler-Ross, 2005 apud Hohendorff \& Melo, 2009). Desse modo, Silva (2003) apud Hohendorff e Melo (2009), destaca que tal posicionamento diante da morte, somente contribui para a inaptidão ao lidar com a finitude.

Falar e pensar sobre a morte, a finitude do homem, é, além de desafiador, extremamente doloroso, principalmente quando a cultura supervaloriza a vida e não possibilita o discurso e reflexão sobre o morrer. Santos (2011) apud Levisk e Langaro (2014), traduz a dificuldade do assunto em questão, uma vez que este germina o desalento ao constatar-se como um ser finito engendrando a insegurança.

Apesar de fazer parte do desenvolvimento humano, a morte ocupa um lugar de negação (Combinato \& Queiroz, 2005; Quintana \& Arpini, 2002 apud Hohendorff \& Melo, 2009). Um dos motivos pelos quais isso ocorre são os aparatos e conhecimentos tecnológicos que possibilitam um prolongamento da vida e a medicina que cada vez mais tenta intrujar a morte (Bellato \& Carvalho, 2005 apud Hohendorff \& Melo, 2009). Os médicos são formados para curar e sempre manter a vida; a morte, nesse sentido, toma o lugar de um fracasso profissional, que pode ser também levado como um fracasso pessoal. Os familiares raramente entendem que chegou a hora temida e questionam apontando os profissionais de saúde. Estes comportamentos são frequentes em unidades que lidam com o fato, e a falta de discussão e reflexão nos contextos sociais permite que a morte continue no lugar de negação. Todos sabem que ela existe, todos sabem que o caminho da vida leva para ela, mas pouquíssimos querem refletir sobre, se esquivar tem sido o "melhor" comportamento desde sempre.

De qualquer modo, a complexidade para os que ficam em vida diante da finitude do outro é deparar-se com o seu futuro, sem saber ao certo quando e como será, além de vivenciar a ausência, a perda, a falta daquele que já se foi. 
Gennep (2011) apud Giamattey, 2020, entende a morte como um processo e o luto como acompanhante dela, sendo assim, o luto é visto também como um processo, não sendo estático, sempre em movimento, que vai abrangendo as respostas frente à perda. Fukumitsu (2012) apud Bastos (2019) entende o luto como:

Um processo de ajustamento e elaboração do sentimento de pesar perante a perda. O luto encontrase ao lado da morte, como evento, e ao lado da vida como processo. É um percurso de mão dupla, uma busca perseverar pela lembrança, a outra busca a abertura para a construção de novos laços afetivos.

Compreender o luto e a morte como processos, e não como estados estáticos e imutáveis, é importante para abarcarmos que esse movimento traz mudanças. As perdas não são de todo subtração, à medida que fazem o homem olhar o seu mundo interno diferente e aperceber o mundo externo diferente e o fazem modificar. Perder é também dar um novo significado e uma nova organização, as lacunas deixadas são preenchidas, todas as coisas morrem e todas as coisas são recompostas.

Não obstante, no momento em que o mundo vive desde 2020, a morte em massa e o luto coletivo têm estado no cotidiano social. Falar em morte não é mais uma opção a ser negada. Um autor desconhecido apud Soares \& Mautoni (2013), deixou a seguinte reflexão:

Krisha Gotami era uma jovem que viveu na época de Buda. Quando seu filho único morreu, ela procurou desesperadamente alguém que pudesse trazê-lo de volta á vida. Por fim, pediu a Buda. Este mandou que ela trouxesse uma semente de mostarda de uma casa que nunca houvesse experimentado a morte. Batendo de casa em casa, a mulher ouvia sempre a mesma história: "Podemos lhe dar quantas sementes quiser, mas a condição não será cumprida, pois muitas pessoas já morreram em nossa família”. Ela insistiu, ainda com esperança, e continuou sua busca, mas finalmente percebeu a verdade: a morte faz parte da vida e acomete a todos os mortais; assim, ninguém está verdadeiramente sozinho na dor. Então, voltou ao Buda. “Onde estão as sementes?”, perguntou ele. A jovem caiu aos seus pés dizendo: "Entendi sua lição. Agora estou pronta para conhecer aquilo que nunca morre. Não peço mais pela volta do meu filho, pois mesmo que isso me seja concedido ele morrerá novamente um dia. Ensina-me algo de tal modo que agora eu possa conhecer dentro de mim mesma aquilo que nunca morre." A mulher descobriu então que manter o filho na memória, lembrando todos os detalhes de sua vida, o manteria vivo... Ausência se fazendo presença. Se o esquecesse, aí sim ele morreria! Mais calma, a jovem senhora suportou a dor da perda, entendendo que se ficasse paralisada teria uma morte em vida, que deveria seguir em frente, criando novos projetos para sua existência.

A morte visita todas as famílias. Todavia, neste ciclo que o mundo vivencia, ela não apenas tem feito visitas mais frequentes, como também tem deixado uma ferida nos que sobrevivem, a qual se trata da ausência dos rituais fúnebres como um dia foram elaborados. O espaço uma vez concedido para a dor ser expressa está mais restrito, e até ausente.

Nos hospitais, os profissionais de saúde que estão próximos nesses momentos muito ouvem o lamento daqueles que desejam ao menos vestir seus mortos, contudo, são impedidos pelo caos instalado. Atualmente, o número de mortos por COVID-19 ultrapassa 3 milhões no mundo, e no Brasil já soma-se mais de 425 mil. Como encarar a perda e a falta dos rituais?

É observando como a sociedade se coloca diante dos rituais fúnebres que se torna possível perceber como se comporta diante do percurso da vida, no qual a morte está inclusa. A vida pode ser entendida observando como a finitude é vista no social. É bem verdade que padronizar e generalizar neste quesito não é possível, pensando que o homem é um ser subjetivo e cada qual vivencia tal momento à sua maneira. Ainda assim, não se deve descartar a importância de uma visão panorâmica acerca dele.

Quando se trata de rituais, o assunto vai muito além do que se é visto e posto. Todo ritual tem seu poder e função simbólica. Bryard (1996) apud Souza e Souza (2019) diz que “o rito fúnebre é, a princípio, o gesto técnico de lavar, enterrar e cremar o cadáver, mas é o seu prolongamento para o ato simbólico que o torna abrangente em todo o seu sentido". Ou seja, visivelmente, são objetos, lugar, pessoas que aparecem, todavia, esse período de chorar e exprimir o sofrimento ocasionado pela perda em um ambiente seguro para tal é o princípio de simbolizar o momento do novo ciclo, esquadrinhando um sentido.

Quando se perde alguém para a finitude, se vai tudo o que se era somente com aquela pessoa e esse momento exige uma ressignificação e reorganização. Para esse fim, existem os rituais. Imber-Black (1998) apud Souza e Souza (2019), aponta que as funções deles são: "marcar a perda, afirmar a vida, facilitar a 
expressão do luto, falar sobre a morte e sobre a vida, apontar uma direção que faça sentido diante da perda e da continuação da vida dos que ficaram".

As experiências que os rituais viabilizam se revelam significativas nas passagens dos ciclos da vida, segundo Bromberg (2000) apud Souza e Souza (2019), uma vez que permitem o estabelecimento de um elo entre passado e futuro e agrupam significados tanto na família como na cultura.

Bromeberg (2000) apud Souza e Souza, (2019), sinaliza que:

"O uso de rituais como recurso terapêutico envolve três aspectos, sendo eles: um ritual para admitir a perda e entrar no luto; um ritual que simbolize o que os familiares incorporaram do morto; um ritual para simbolizar os momentos de mudança na vida."

Catroga (2020) apud Giamattey (2021), define:

"Ritos como comportamentos complexos que espelham os afetos mais profundos e guiam o defunto no seu destino post-mortem e tem como objetivo fundamental superar o trauma e a desordem que toda a morte provoca naqueles que ficam vivos."

Diante do exposto, é notável que os rituais são de alta relevância na vida social. É nesse momento que se dá abertura ao processo de luto. É a oficialização da perda. Soares e Mautoni (2013), aponta que o momento dos rituais é importante para que o luto seja processado de forma lenta e saudável. Longaker (1998), apud Soares e Mautoni (2013), corrobora afirmando que o luto não terminará se nem começar.

Faz-se necessário anuir que a morte sobreveio. Com isso, é significativo que a experiência física e tateável da realidade ocorra. Quando não ocorre, a possibilidade de que o sentimento seja suprimido e a dor negada é alta e os efeitos são reais. Assim sendo, ver o corpo no hospital, em casa ou no funeral ampara a aceitação e a elaboração da realidade da perda (Soares \& Mautoni, 2013).

$\mathrm{O}$ que por vezes transcorre nos funerais são as pessoas próximas doparem os familiares que sofrem a perda. É realmente complexo e difícil estar presente no momento de dor, em contrapartida, é de suma importância que os enlutados estejam conscientes do que está ocorrendo. É preciso que estes entrem em contato com os seus sentimentos e tenham a oportunidade de expressar as suas dores (Soares \& Mautoni, 2013).

Um dos grandes males da sociedade é exigir que o sobrevivente controle as emoções ao ponto de não as expressar, sendo que este fato pode corroborar para um agravamento e possível complicação. Grollman (2005) apud Soares e Mautoni (2013), afirma que "luto compartilhado é luto amenizado." Gozar a factualidade da perda é essencial para a elaboração do luto (Soares \& Mautoni, 2013).

"O luto é uma desistência provisória do mundo, uma existência a mínima sob a égide da tristeza, mas é passageiro" (Breton, 2018). Breton avalia o luto como um momento de desaparecer de si e do mundo de forma aceitável. Embora os comportamentos do sujeito estejam anormais, eles se tornam incontestáveis. Viver o estado de luto é cuidar da saúde mental, tendo tempo para ressignificar a vida e planejar a caminhada adiante, a qual jamais será igual.

\section{Diferentes rituais fúnebres e manifestações do luto}

Sempre existiu em toda a cultura uma intensidade na despedida de seus mortos. Embora haja diferentes formas de fazê-la ao redor do mundo, ela nunca deixa de existir.

Com a pandemia, a necessidade de mudar a maneira de despedir-se, de forma abrupta, gera no homem um grande mal estar, relatado por um grande número de familiares, sendo o aumento na busca por profissionais da área de saúde mental um reflexo que essas privações bruscas têm ocasionado.

Para as famílias enlutadas, o velório tem soado como algo "expresso", rápido demais para se despedir, limitado e restrito para o último adeus, sendo que o toque e o olhar o corpo no caixão não podem acontecer. Não é mais possível que os próprios familiares levem o seu morto até seu novo "quarto", as roupas, que caracterizam a identidade, também não são mais usadas. Os velórios e manifestações de luto precisaram ser alterados e isso, para muitos, resulta em angústias inomináveis.

"A pandemia cria situações inusitadas, entre elas a de mortes sem funerais. Como é possível ficarmos alheios a um rito de passagem tão ancestral, exclusivamente humano? Na natureza, nenhum outro ser chora os seus mortos e os reverencia no sepultamento" (Betto, 2020). 
Segundo Menezes e Gomes (2012) apud Giamattey, (2020), em todos os lugares do mundo em que existem grupos de pessoas, comunidades, sociedades, a morte é um evento; quando algum familiar morre, seu círculo social responde de forma ordenada embasada em que o grupo sente e acredita. A cultura age como referência e determina os procedimentos de cuidados com o corpo e seu destino, e também é o norte de estruturação e formulação para o período de luto.

O que a pandemia está fazendo é se intrometer e alterar todo o processo de condução dos rituais fúnebres. O artigo Antígona e Antares, publicado no O Globo (2020), e o Jornal Folha de São Paulo, 16/05/2020, na matéria "Na África, funerais são tão importantes quanto casamentos. A pandemia os esvaziou”, trazem os seguintes relatos:

"Agora, o vírus nos rouba tudo isso que traduz nossos laços de parentesco e amizade: visitar o enfermo, consolá-lo e animá-lo, preparar o corpo para o funeral, promover o velório, cumprir os rituais de enterro ou cremação, ver o caixão descer ao túmulo, orar em conjunto pelo falecido, e manifestar condolências e abraçar os mais afetados pela perda” (Betto, 2020).

"Em diversos países da África, o combate à Covid-19 alterou tradições funerárias que mesclam rituais de religiões locais com elementos cristãos introduzidos pela colonização europeia do século 19 [...] O funeral na África é algo comunitário, não individual. Porque, quando alguém morre, a comunidade toda sente o luto e divide a tristeza com a família do falecido", diz Sihawukele Ngubane, professor da Universidade de Kwazulu-Natal, na África do Sul” (Perassolo \& Ferraro, 2020).

"Você precisa que as pessoas venham, lhe confortem e lhe encorajem, para que a dor da passagem do ente querido seja curada" (Perassolo \& Ferraro, 2020).

A abstinência de vivenciar os marcos de uma maneira culturalmente harmônica, os quais visam cumprir seu papel de organização para o processo de luto, tende a aumentar as chances de luto complicado. Os rituais fúnebres fazem parte da "aprovação social" para a expressão da dor da perda e iniciar a elaboração de uma nova vida que se configurará a partir da morte.

O velório é a oportunidade que a família tem de prestar suas últimas homenagens e trazer o discurso de quem foi a pessoa em vida e assim contribuir para a narrativa da perda. A escolha do caixão e todos os preparativos para que o velório aconteça têm a ver com quem foi o morto e com o modo como a família se sente ao organizar tudo conforme se acredita que o defunto gostaria que acontecesse. Todo esse processo tem seu significado e importância na elaboração.

Alguns jornais trazem relatos de familiares e trabalhadores na área dos rituais, os quais demonstram o quanto tem sido sofrido e desafiador essa nova configuração.

“Hoje com 25 anos, Leonardo [sepultador do Cemitério São Francisco Xavier, no Caju, Rio de Janeiro] [...] Não está conseguindo se habituar à solidão dos enterros das vítimas da Covid-19. Para o sepultador, é difícil trabalhar acompanhado por um único parente do morto [...] - A ausência dos familiares é o mais triste. Quem vem para o enterro traz o sofrimento da família toda. O risco de contaminação mudou tudo. É algo anormal. Isso mexe com a gente - admite o sepultador" (Ribeiro, 2020).

Toda essa privação pode ocasionar transtornos emocionais para os enlutados e também para os trabalhadores mais diretos nesse novo cenário. Não obrigatoriamente o processo de luto, os rituais e enterros determinam a não desenvolver um transtorno emocional e/ou um luto complicado, contudo esses eventos que confirmam a morte se fazem importantes. O desejo é fomentar que a vivência do processo de luto, em suas mais variadas formas, é relevante no sentido da saúde mental (Giamattey, 2020).

A psicóloga Erika Pallottino participa de uma reportagem no Jornal O Globo, na matéria - Velório virtual, orações por aplicativo e grupos de apoio online: o 'novo' luto durante a pandemia do coronavírus, da qual descrevo um trecho abaixo:

"A impossibilidade de acompanhar os doentes no hospital ou de se despedir caso o quadro se agrave cria um "traço traumático que é a morte súbita, inesperada". Ela afirma que especialistas no exterior dão uma perspectiva de dez anos de impacto da pandemia na saúde mental das pessoas, muito ocasionada pela resposta de luto" (Tatsch, 2020).

Profissionais da área de saúde mental estão empenhados em estudar e orientar a melhor forma de condução, respeitando a singularidade. Algumas cartilhas foram disponibilizadas e muitas estão sendo utilizadas. Com a pandemia, diferentes maneiras de rituais de despedida estão sendo formuladas (Giamattey, 2020). 
A cartilha da Fundação Oswaldo Cruz (2020) apresenta os rituais fúnebres online como método remoto de despedida diante da impossibilidade de proximidade, uma vez que, além de completar as lacunas das homenagens aos mortos, reintegra, ao menos em parte, a sensação de comunhão e partilha que o momento demanda, auxiliando simultaneamente aqueles que continuam vivos (Giamattey, 2020).

\section{Considerações finais}

Considerando a discussão acima, a qual enfatiza a importância do ritual fúnebre, a sua simbologia, o que o próprio momento proporciona e o estar acompanhado de pessoas queridas em um ambiente que lhe permite o comportamento esperado da perda, compreende-se que a ausência do ritual ocasiona uma incerteza que pode perdurar e tornar o luto em luto complicado.

A abstinência dos rituais tem um grande impacto no inicio do processo de luto e pode gerar questões mentais complexas. A necessidade destes se dá como uma maneira de organização e inicio de uma ressignificação. Se não há possibilidade, diante do cenário atual, de um ritual como sempre ocorrera, faz-se relevante pensar em novas maneiras de realizá-lo, pois negligenciá-lo é um risco grande à saúde mental dos enlutados.

Falar sobre morte, luto e perdas é de alta relevância para a vida.

\section{Referências}

Bastos, A. C. S. B. 2019. Na iminência da morte: Cuidado Paliativo e Luto. Antecipatório para crianças/adolescentes e os seus cuidadores. Tese (Doutorado em Psicologia), Universidade Federal da Bahia, Instituto de Psicologia, Salvador, 245p.

Breton, D. L. 2018. Desaparecer de si: uma tentação contemporânea. Tradução Francisco Morás. Petrópolis, RJ: Vozes, 99p.

Fundação Oswaldo Cruz. 2020. Processo de luto no contexto da COVIDA-19. Disponível em: https://www.fiocruzbrasilia.fiocruz.br/wp-content/uploads/2020/04/Sa\%C3\%BAde-Mental-e-

Aten\%C3\%A7\%C3\%A3o-Psicossocial-na-Pandemia-Covid-19-processo-de-luto-no-contexto-da-Covid19.pdf. Acesso em: 13 jun. 2021.

Giamattey, M. E. P. 2020. Processo de Luto diante da ausência de Ritual Fúnebre na Pandemia da COVID-19: análise documental jornalismo online. Dissertação de Mestrado Profissional em Saúde Mental e Atenção Psicossocial. Florianópolis, SC: Universidade Federal de Santa Catarina.

Hohendorff, J. V., \& Melo, W. V. 2009. Compreensão da morte e desenvolvimento humano: contribuições à psicologia hospitalar. Estudos e Pesquisas em Psicologia, 9(2), 480-492.

Levisk, B. L., \& Langaro, F. 2014. O olhar humano sobre a vida: a consciência da finitude. Revista da SBPH, 17(1), 49-69.

Perassolo, J., \& Ferraro, M. 2020. Na África, funerais são tão importantes quanto casamentos. A pandemia os esvaziou. Disponível em: https://www1.folha.uol.com.br/mundo/2020/05/na-africa-funerais-sao-taoimportantes-quanto-casamentos-a-pandemia-os-esvaziou.shtml. Acesso em: 13 jun. 2021.

Ribeiro, G. 2020. Coronavírus: 'Ausência de familiares é o mais triste' conta sepultador do Caju sobre sua nova rotina no cemitério. O Globo, Rio de Janeiro. Disponível em: https://oglobo.globo.com/rio/coronavirusausencia-de-familiares-o-mais-triste-conta-sepultador-do-caju-sobre-sua-nova-rotina-no-cemiterio24425947. Acesso em: 13 jun. 2021.

Betto, F. 2020. Artigo: Antígona e Antares. O Globo, Brasil. Disponível em: https://oglobo.globo.com/sociedade/artigo-antigona-antares-24395691. Acesso em 13 jun. 2021.

O Globo. 2020. Artigo: Antígona e Antares. Disponível em: https://oglobo.globo.com/sociedade/artigoantigona-antares-24395691. Acesso em: 13 jun. 2021.

Tatsch, C. 2020. Velório virtual, orações por aplicativo e grupos de apoio online: o 'novo' luto durante a pandemia do coronavírus. O Globo, Rio de Janeiro. Disponível em: https://oglobo.globo.com/sociedade/coronavirus/velorio-virtual-oracoes-por-aplicativo-grupos-deapoio-online-novo-luto-durante-pandemia-do-coronavirus-24385878. Acesso em 13 jun. 2021.

Soares, E. G. B., \& Mautoni, M. A. A. G. 2013. Conversando sobre o luto. São Paulo: Ágora. 
Souza, C. P., \& Souza, A. M. 2019. Rituais Fúnebres no Processo do Luto: Significados e Funções. Psicologia Clínica e da Cultura, 35, e35412.

\section{Minicurrículo}

Priscila Caroline Cordeiro Mendes. Possui graduação em Psicologia pelo Centro Universitário Jorge Amado (2015). Especialização em Psicologia Infantil pela UnyLeya (2017). Especialização em Psicologia Hospitalar e da Saúde pela Faculdade Única de Ipatinga (2021). Membro do NIPED (Núcleo de Intervenções Psicológicas em Emergências e Desastres). Experiência em atendimento psicológico clínico e hospitalar. Experiência em UTI COVID.

Como citar: Mendes, P.C.C. 2021. Abstinência dos rituais fúnebres e seus impactos. Pubsaúde, 7, a236. DOI: https://dx.doi.org/10.31533/pubsaude7.a236

Recebido: 03 ago. 2021.

Revisado e aceito: 24 ago. 2021

Conflito de interesse: os autores declaram, em relação aos produtos e companhias descritos nesse artigo, não ter interesses associativos, comerciais, de propriedade ou financeiros que representem conflito de interesse.

Licenciamento: Este artigo é publicado na modalidade Acesso Aberto sob a licença Creative Commons Atribuição 4.0 (CC-BY 4.0). 